\title{
Rosette formation by circulating lymphocytes from rheumatoid and nonrheumatoid subjects
}

\author{
D. J. LEA AND D. J. WARD \\ Robert Jones and Agnes Hunt Orthopaedic Hospital, Oswestry, Salop.
}

In the majority of patients with rheumatoid arthritis the immune response is most readily detected as a production of rheumatoid factors, IgM antibodies, which agglutinate to high titre erythrocytes coated with IgG antibodies from man, rabbit, or sheep, etc. Generally, only low titres of rheumatoid factors are found in nonrheumatoid individuals. Bach, Delrieu, and Delbarre (1970a, b) described circulating human lymphocytes which bear surface receptors with antiglobulin activity. Upon mixing and centrifuging with human erythrocytes coated with rabbit antibody, each lymphocyte was surrounded by adherent erythrocytes to form a rosette; usually fewer than six rosetteforming lymphocytes per thousand were found in control subjects, whereas over 70 per cent of patients with rheumatoid arthritis gave greater numbers. Patients with gout gave increased rosette counts. These authors suggested that the lymphocyte response of the rheumatoid individual precedes the appearance of humoral rheumatoid factors and that the process may correspond to that found in animals after immunization (Brown and Epstein, 1969).

In order to examine the properties and occurrence of rosette-forming lymphocytes, we have tested lymphocyte preparations from normal subjects of various ages, patients suffering from rheumatoid arthritis, and patients with orthopaedic conditions not related to rheumatoid arthritis.

\section{Material and methods}

The ability of human lymphocyte preparations to form rosettes was measured by allowing a mixture of washed lymphocytes and antibody-coated erythrocytes to sediment gently (Lamvik and Godal, 1970), re-suspending, and examining in wet film by darkground illumination.

Lymphocytes were isolated from fresh heparinized blood either directly or after enrichment by sedimentation of erythrocytes using Plasmagel (Tosi, Pellegrino, Scudeller, and Ceppellini, 1967). Density centrifugation by the method of Fröland and Natvig (1970) gave generally low

Accepted for publication October 12, 1971. yields of lymphoyctes, but although the method did not give reproducibly less than 1.5 per cent. granulocytes, contamination was usually quite small. Lymphocytes isolated by this method were washed three times in Hanks's or Eagle's medium, re-suspended in the residual supernatant, and adjusted to $8,000 \mathrm{cell} / \mathrm{mm}^{3}$.

Human OD+ erythrocytes were sensitized with immune Ripley anti-CD serum (kindly supplied by Dr. Marion Waller) for $1 \mathrm{hr}$ at $37^{\circ} \mathrm{C}$. (Waller and Vaughan, 1956), washed once, and then used immediately at 1 per cent. concentration. Sheep erythrocytes were sensitized with glycerinated rabbit amboceptor serum (Wellcome) by keeping at room temperature for $\mathbf{3 0}$ minutes or more a mixture containing 1 per cent. cells and a suitable concentration of serum. To avoid possible agglutination, this cell suspension was not centrifuged before use. Unlike Bach and others (1971) we used a dose of rabbit amboceptor which gave optimum sensitization for the Waaler-Rose test as determined with a reference panel of sera. This antiserum concentration was unrelated to the haemagglutination titre (Cathcart and O'Sullivan, 1965).

None of the above preparations contained active complement.

In the test one drop of lymphocyte suspension about 3 hours old was mixed with one drop of 1 per cent. erythrocytes in Hanks's or Eagle's medium in a small conical tube, kept 1 hour at room temperature, re-suspended very gently, and then examined using darkground illumination. Although rosettes could be seen directly, the addition of 0.001 per cent. acridine orange to the suspension and the use of blue/ultraviolet illumination (Schott BG12 filter) allowed the rosettes to be seen and counted easily. When alternative ultraviolet (UG1) or yellow filters were used, the number of erythrocytes in a rosette and the type of leucocyte at the centre could easily be seen (Fitzpatrick, Connolly, Lea, O'Sullivan, Augustin, and Macaulay, 1967). Because adherent erythrocytes in rosettes could generally be distinguished from touching erythrocytes, rosettes were taken to contain three, rather than four, erythrocytes.

\section{Results}

No rosettes were formed between lymphocytes and human OD+ cells, but with Ripley IgG-coated 
erythrocytes, rosette-forming lymphocytes constituted 2.5 to 15 per cent. of the total and there was no difference distinguishable between rheumatoid (9) and nonrheumatoid (27) subjects. Cell preparations containing 2.5 per cent stored human serum usually gave decreased rosette counts. Many rosette-forming cells were unequivocally identified as small lymphocytes.

Using normal sheep cells, many rosette-forming lymphocytes were found in some preparations. With sheep cells sensitized with rabbit antibody, up to an additional 25 per cent. of the lymphocytes formed rosettes. In both cases the numbers of rosette-forming lymphocytes appeared to be unrelated to the age or clinical state of the donor. Controls for the experiments with sensitized cells contained either sheep cell-absorbed stored normal rabbit serum or no added serum and washed normal sheep cells.

Lymphocytes from two nonrheumatoid donors were isolated by using Plasmagel and the supernatants were separated by density centrifugation in the usual way. Virtually all these lymphocytes separated in the expected density fraction, supporting our belief that no specific fraction of the lymphocytes was lost in the usual isolation procedure. The percentage of these lymphocytes which formed rosettes with Ripley anti-CD coated human erythrocytes was in the same range as for those separated by density centrifugation alone.

\section{Discussion}

Like Bach and others (1970a, b) we have demonstrated that leucocyte preparations containing predominantly small lymphocytes are able to form rosettes with erythrocytes coated with antibody in a system containing no active complement and that the surface receptors behave like bound rheumatoid factor and may be inhibited by human serum. We have further shown that erythrocytes coated with rabbit antibody or with human antibody are effectively bound by small lymphocytes.

In our experiments the number of rosette forming lymphocytes in a preparation could not be related to the age or clinical condition of the subject. The numbers were almost invariably far larger than in the lymphocyte preparations of Bach and others, which could not be accounted for simply by our slightly different criterion for identifying a rosette-forming cell.
It seems unlikely that the marked lymphocyte reactivity we have observed arose from the different sensitized erythrocytes we used. All three rosette tests were analogues of standard haemagglutination tests for rheumatoid factors - the Waaler-Rose test using rabbit antibody coated sheep cells, sensitized human cell (S.H.C.) test using human antibody (Ripley) coated human cells, and the human erythrocyte agglutination (H.E.A.T.) test using human cells coated with rabbit antibody. Just as the simple Waaler-Rose haemagglutination test gives a high background agglutination because of 'natural' antisheep cell antibody, so the sheep cell rosette test gave a high background with nonsensitized cells, even in the presence of absorbed stored normal rabbit serum at low concentration. Similar results have been reported by Brian and Gordon (1971) and other workers.

We are unable to explain our findings on rosetteforming lymphocytes as the display of an early stage of immunity in rheumatoid arthritis. Small lymphocytes isolated in the manner we have described would seem to behave in a similar fashion to the normal human large lymphocytes described by LoBuglio, Cotman, and Jandl (1967), which bind human antibody-coated human erythrocytes. We could demonstrate inhibition by Ripley serum of rosette formation with Ripley antibody-coated erythrocytes in several, but not all, of the preparations we examined in this way, suggesting that antigen competition occurred. It would be of interest further to examine the specificity of the lymphocyte receptors to see if, as with rheumatoid factors, common determinants of several mammalian IgGs are recognized.

The normal rosette forming large lymphocytes described by LoBuglio and others (1967) are characterized also by their ability to adhere to a plastic surface. It may be that lymphocyte isolation procedures, which incorporate a column procedure for trapping adherent cells, no longer give a representative sample of the population with respect to rosetteforming ability.

\section{Summary}

Circulating small lymphocytes displaying surface antiglobulin activity have been isolated from rheumatoid and nonrheumatoid subjects alike. The reported appearance in rheumatoid arthritis of increased numbers of such cells which form rosettes with antibody-coated erythrocytes could not be confirmed.

\section{References}

Bach, J. F., Delrieu, F., ANd Delbarre, F. (1970a) Presse med., 78, 301 (Le phénomène de la rosette rhumatoïde. I. Nouvelle méthode de détection du facteur rhumatoïde au niveau cellulaire)

$-, \ldots,-$, , (1970b) Amer.J. Med., 49, 213 (The rheumatoid rosette; a diagnostic test unifying seropositive and and seronegative rheumatoid arthritis)

BraIn, P., AND GoRDON, J. (1971) Clin. exp. Immunol., 8, 441 (Rosette formation by peripheral lymphocytes, II. Inhibition of the phenomenon) 
Brown, J. C., AND EpsteIn, W. V. (1969) Arthr. and Rheum., 12, 1 (Influence of human rheumatoid factor on numbers of antibody-producing cells)

CAthCART, E. S., AND O'Sullivan, J. B. (1965) Ibid., 8, 530 (Standardization of the sheep cell agglutination test; the use of pooled reference sera and haemagglutination trays)

Fitzpatrick, M. E., Connolly, R. C., Lea, D. J., O’Sullivan, S. A., Augustin, R., and Macaulay, M. B. (1967), Immunology, 12, 1 (In vitro detection of human reagins by double layer leucocyte agglutination: method and controlled blind study)

Fröland, S. S., AND NATVIG, J. B. (1970) Int. Arch. Allerg, 39, 121 (Effect of polyspecific rabbit anti-immunoglobulin antisera on human lymphocytes in vitro)

LAMVIK, J. O., AND Godal, T. (1970) Acta path. microbiol. scand., Sect. B., 78, 560 (Effect of centrifugation on the immune reaction of rabbit blood lymphocytes following antigen stimulation in vitro)

LoBuglio, A. F., Cotran, R. S., AND JANDL, J. H. (1967) Science, 158, 1582 (Red cells coated with immunoglobulin $\mathrm{G}$ : binding and sphering by mononuclear cells in man)

Tosi, R. M., Pellegrino, M., Scudeller, G., ANd Ceppellini, R. (1967) In 'Histocompatibility Testing, 1967', ed. E. S. Curtoni, P. L. Mattiuz, and R. M. Tosi, p. 351. Munksgaard, Copenhagen

Waller, M. V., and Vaughan, J. H. (1956) Proc. Soc. exp. Biol. (N.Y.), 92, 198 (Use of anti-Rh sera for demonstrating agglutination activating factor in rheumatoid arthritis) 